mag. Daniela

Brečko

GV Izobraževanje

\title{
SOCIOKRONOLOŠKA IZHODIŠČA ZA NAČRTOVANJE KARIERE
}

\section{Posameznikov biosocialni življenjski cikel in načrtovanje kariere}

$\mathbf{N}$ posameznikovega biosocialnega razvoja. Celo nasprotno. Načrtovanje življenjske poti je v tesni povezavi z njegovim biosocialnim stanjem in vpliva na vse njegove odločitve ne glede na to, ali se tega zaveda ali ne. Vsakdo bi moral namreč pomisliti na svoje bivanje $\mathrm{v}$ svetu, pri čemer se v posameznih obdobjih bivanja pojavljajo problemi, ki jih mora rešiti. Starejši sistemi načrtovanja karier, ki so jih snovali v organizacijah, so imeli veliko slabost, temeljili so namreč na predpostavki, da lahko posameznika iztrgamo

Pri načrtovanju osebne kariere moramo upoštevati posameznikov biosocialni razvoj. iz zasebnega življenja, od njegove družine in mu potemtakem moramo omogočati le poklicni razvoj. Ko so raziskave o osebnostnem razvoju odraslih napredovale, je postajalo vse jasneje, da so delo, družina in posameznikovo samozavedanje $\mathrm{v}$ tesni povezavi in da vsi ti dejavniki zelo vplivajo tudi na delo in odločitve $\mathrm{v}$ zvezi $\mathrm{z}$ njim. Ta interakcije preprosto ne moremo več ignorirati. Na delo namreč ne prihaja le del posameznika, ampak je njegova uspešnost odvisna od njegovega psihofizičnega stanja, na katerega pa nedvomno vplivajo vsi dogodki $\mathrm{v}$ posameznikovem življenju. Prav zato bomo $\mathrm{v}$ nadaljevanju predstavili koncept življenjskega cikla, ki mu je podvržen $\mathrm{z}$ večjimi ali manjšimi odmiki vsakdo $\mathrm{v}$ življenju, še posebej zato, ker ima močan vpliv na odločitve $\mathrm{v}$ zvezi s kariero.

\section{KONCEPT ŽIVLJENJSKEGA CIKLA}

Vsako mora $\mathrm{v}$ življenju računati na probleme, ki jih bo moral v posameznih starostnih obdobjih reševati. $\mathrm{V}$ zahodni kulturi lahko te probleme delimo na tri temeljne kategorije:

1. Problemi, ki izvirajo iz procesa biološkega staranja in socialnih procesov, povezanih s tem. Z biološkim zorenjem in staranjem so povezane določene, predvidljive spremembe $\mathrm{v}$ našem telesu, najočitnejše so $\mathrm{v}$ obdobju pubertete in menopavze. Prav tako lahko pričakujemo, da bomo s starostjo dovzetnejši za nekatere kronične bolezni, kot so bolezni srca in ožilja. Biološko staranje spreminja »kemijo« našega telesa in te spremembe se kažejo tudi v našem čustvenem in doživljajskem svetu. Sočasno pa so vse zahodne družbe razvile zelo kompleksen sistem starostnih obdobij pričakovanja, trdno zasidrana $\mathrm{v}$ posameznih družbah, ki določajo, kakšne naloge naj bi posameznik v določenih obdobjih izpolnjeval in kako naj bi se vedel v različnih starostnih obdobjih (Neugarten, 1968, Havighurst, 1972). Veliko raziskovalcev je svoje delo posvetilo raziskovanju življenjskih nalog, ki jih družba in kultura nalaga posamezniku. Najsistematičnejšo razdelitev je ponudil Havighurst, ki deli življenje posameznika na tri ve- 
čja kronološka obdobja in vsakemu izmed teh obdobij pripiše šest do osem pomembnih življenjskih nalog, ki jih mora, če želi biti cenjen član družbe, izpolniti.

Tudi pričakovanja glede vedenja se spreminjajo glede na starost. Tako se od otroka pričakuje, da je zelo čustven, impulziven in igriv, od adolescenta, da bo nekoliko zmeden, razdražljiv in »izgubljen«, od odraslega, da bo razumen, odgovoren do dela in družine, od starejših ljudi pa, da bodo počasi zapustili svet dela, več časa posvetili aktivnostim $\mathrm{v}$ prostem času in tudi sprejeli postopno prenašanje odgovornosti na svoje naslednike. Te biološke sile in pričakovanja družbe oziroma kulture sestavljajo del posameznikovega biosocialnega cikla, ki ima največ opraviti tudi z individualnim osebnostnim razvojem.

\section{Problemi, ki zadevajo posameznikovo} razmerje do družine. $V$ zgodnji odrasli dobi se srečujemo $\mathrm{z}$ družinskimi problemi, ki se nanašajo na starše in doseganje osebne neodvisnosti. Ko si ustvarimo lastno družino, pa se srečujemo s problemi vzgoje lastnih otrok, iz katere izvirajo nove odgovornosti. Pri tem pa stari problemi ne izginejo, celo nasprotno, s staranjem staršev postajo še večji. Na eni strani nas pesti skrb za lastne otroke, na drugi strani za ostarele starše, ki postajajo vse odvisnejši. Tako vsi živimo v nekakšnem družinskem ciklu, čeprav nimamo lastne družine. Družinski cikel pred nas postavlja določene naloge in probleme, ki izhajajo iz njega in ki jih moramo reševati. Očitno je, da so problemi, povezani z družinskim ciklom, tesno povezani s posameznikovim biosocialnim razvojem, toda koristno je, da jih obravnavamo posebej, predvsem zato, ker iz vlog, ki nam jih narekuje družinski cikel, preprosto ne moremo izștopiti, kakor na primer lahko izstopimo iz poklicne vloge, in moramo najti ustrezen način, da vloge učinkovito »odigramo《.

3. Tretja skupina problemov, na katere moramo računati, pa so problemi, poveza- ni $\mathbf{z}$ delom in razvojem kariere. Ti problemi so bili v preteklosti bolj na ramenih moških, toda danes postajajo ravno tako ali pa še pomembnejši za ženske. Plačano delo je namreč še vedno temelj, s katerim družba omogoča preživetje posamezniku in družini. Delo je integrirano $\mathrm{v}$ posameznikovo življenje, toda obravnavam ga ločeno od drugih dveh ciklov, predvsem zato, ker pritiski in priložnosti, ki izhajajo iz kariernega cikla, niso niti pod nadzorom posameznika niti njegove družine.

Nasprotno, izhajajo iz socialnih definicij potreb, ekonomskih institucij, tradicije in politike, vgrajenih $v$ izobraževalni sistem, in specifične politike delovnih organizacij samih. Karierni cikel tako vključuje zgodnjo pripravo na poklic $\mathrm{z}$ izobraževanjem in usposabljanjem, obdobje poklicnega življenja z različnimi Življenske naloge
posameznika izha-
jajo iz njegovega
razmerja do
družine, dela in
socialnega okolja. stopnjami in upokojitev in priložnostno seveda tudi novo kariero.

Vsi ti cikli se prepletajo in so $\mathrm{v}$ tesni interakciji drug z drugim. Iz teh interakcij lahko včasih posameznik veliko pridobi, včasih pa so lahko tudi vir težav. Prepletanje treh različnih ciklov vizualizira diagram na str. 62 , ki kaže tri cikle v obliki vzponov in spustov. Spusti pomenijo rutinsko delovanje cikla, vrhovi diagrama pa simbolizirajo izbirno točko ali pa oviro, na katero naleti posameznik. Če na primer določena naloga $\mathrm{v}$ kariernem ciklu zahteva od njega veliko truda in osebne energije, bi bilo idealno, da ga $v$ tem času ne bi doletele še zahtevnejše naloge, ki izhajajo iz drugih dveh življenjskih ciklov. Staro pravilo namreč pravi: lotevajmo se enega problema, in ne več problemov sočasno. Na primer, če se posameznik odloči za poroko in hkrati dobi prvo službo, kar se sicer pogosto dogaja, je pred dvema izjemno pomembnima življenjskima nalogama hkrati. Ena naloga izvira iz kariernega cikla, druga iz družinskega cikla - 
obe pa zahtevata investiranje energije in časa, kar lahko presega njegove zmožnosti. Problem lahko rešuje tako, da enostavno zmanjša vpletenost v en ali drug cikel, ki se lahko manifestira na delovnem mestu ali pa $\mathrm{v}$ družinskem konfliktu.

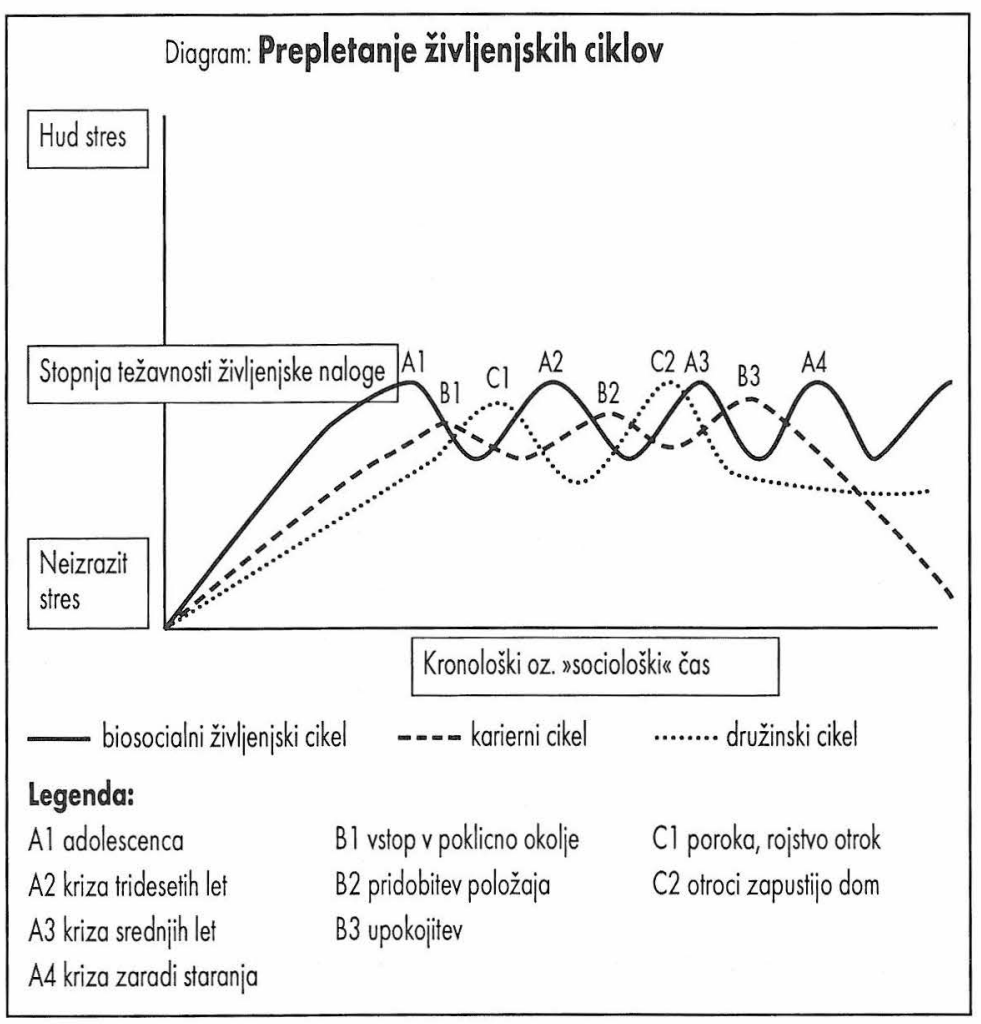

Nekatere teorije osebnostnega razvoja, predvsem teorije zgodnjega oblikovanja osebnosti, ki izhajajo iz Freudove psihoanalitične teorije, zagovarjajo stališče kontinuitete pri reševanju življenjskih nalog (Brečko, 1997). Osebnostni stil reševanja problemov, ki se ga je posameznik naučil v zgodnjem otroštvu, je značilen za reševanje nalog tudi $v$ obdobjih večjih osebnostnih prehodov oziroma tranzicij, kot je prehod v adolescenco, srednja leta, staranje. V prid tej teoriji govori tudi longitudinalna študija (Maas in Kuypers, 1974) z izsledki, da imajo posamezniki, ki so imeli v zgodnjem otroštvu zdravstvene in prilagoditvene težave pogosteje podobne težave tudi ob
Kako se bo posameznik spoprijemal z življenjskimi nalogami, je odvisno od njegovega »biološkega make-upa (zdravja, ravni osebne energije, naravne inteligentnosti, temperamenta in drugih genetskih dejavnikov), izkušenj iz otroštva, fizioloških in čustvenih (prehrane, zdravstvenih težav v otroštvu, čustvenih spodbud staršev ...), socializacije (vrednot in prepričanj, ki si jih je pridobil v otroštvu v krogu družine in šoli, družbi vrstnikov in ki določajo življenjske cilje, ambicije in dajejo smisel njegovim prizadevanjem, da bi te cilje tudi dosegel), nakopičenih izkušenj, ki izhajajo iz že opravljenih življenjskih nalog in družinskih odnosov.

življenjsko pomembnih prelomnicah, še posebej v upokojitveni dobi.

Druge teorije osebnostnega razvoja, predvsem tiste, ki izhajajo iz Jungove teorije, zagovarjajo ravno nasprotno, namreč diskontinuiteto reševanja življenjskih nalog, in poudarjajo neizrabljen osebnostne zmogljivosti kot priložnost za rast v življenju. Po tej teoriji posameznik preseže osebnostni stil reševanja problemov iz otroštva, $\mathrm{k}$ njim se morebiti povrne le $\mathrm{v}$ poznih letih, ni pa nujno. Življenje se po tej teoriji zdi kot kontinuiran proces, $v$ katerem ima vsakdo priložnost, da razvije neizživete zmožnosti. V korist tej teoriji govorijo primeri, ko posamezniki v zrelih letih ali pa v pokoju spoznajo, da imajo v sebi zmogljivosti, ki jim jih med aktivno delovno dobo nikoli ni uspelo realizirati. Povedano z drugimi besedami: za izražanje skritih zmogljivosti jim je preprosto zmanjkalo časa.

Osebni raziskovalni projekt Metke Wachter (2001), v katerem je analizirala karierno pot 20 posameznikov, je pokazal, da so posamezniki, ki so bili sicer zelo uspešni kot pravniki, ekonomisti in finančniki, uspešni tudi $\mathrm{v}$ drugi karieri kot umetniki, pisatelji ... To pomeni, da so morali izkazati zelo visoko stop- 
njo talenta in motivacije na povsem novem področju delovanja.

Še vedno ni zadosti dokazov, kateri model reševanja življenjskih nalog je primernejši, predvsem zato, ker ni dovolj longitudinalnih raziskav, ki bi lahko ponudile odgovor na vprašanje, kako stabilna oziroma labilna osebnost $\mathrm{v}$ resnici je. $\mathrm{Z}$ veliko verjetnostjo lahko rečemo, da lahko $\mathrm{v}$ vsakem posamezniku najdemo področje stabilnosti, ki odseva temeljno učenje in socializacijo $\mathrm{v}$ zgodnjem otroštvu, pa tudi dokaze, da to prvo učenje ne omejuje posameznika na drugih življenjskih področjih (Shein, 1971).

Namen prispevka seveda ni iskati dokaze za ali proti različnim teorijam, temveč predvsem najti modele, ki bi pomagali posameznikom konstruktivno reševati življenjske naloge, ki se jim v življenju ne moremo izogniti.

Temu cilju bi se lahko približali, če bi nam uspelo razviti takšen sistem izobraževanja in usposabljanja odraslih, ki ne bi le odkrival priložnosti za osebnostni razvoj, temveč odrasle tudi usposobil, torej razvil spretnosti in veščine, ki bi jim omogočale, da po teh novih priložnostih posežejo. Še vedno se programi osebnostnega razvoja odraslih preveč površinsko dotaknejo nekaterih splošnih vprašanj o osebnosti, premalo pa usposabljajo posameznike za reševanje konkretnih problemov. V Sloveniji tudi nimamo pravega svetovanja za razvoj kariere v obdobju pred prvo zaposlitvijo. Raznovrstni vprašalniki nam sicer ponujajo (vprašljiv) pogled v naše sposobnosti, nihče pa posameznikom, ki so na začetku kariernega razvoja, ne razloži, s kakšnimi predvidljivimi težavami lahko računajo, še manj, da bi jih na njih sistematično pripravljali.

Prav zato se v nadaljevanju lotevam obširne analize posameznih faz in nalog $\mathrm{v}$ biosocialnem, kariernem ter družinskem življenjskem ciklu, da bi se lahko posameznik pripravil na te naloge, jih predvidel in v skladu s tem tudi bolje načrtoval svojo kariero.

\section{STOPNIE IN NALOGE BIOSOCLAL- NEGA ŽIVLJENISKEGA CIKLA}

Raziskave na področju osebnostnega razvoja, nekatere segajo že v leto 1959, so identificirale razvojne stopnje, skozi katere gremo vsi $\mathrm{v}$ življenju tako ali drugače. Te razvojne faze so pogosto imenovane tudi krize, ki se kažejo $\mathrm{v}$ težavnosti življenjskih nalog. Teoretična podlaga za koncept biosocialnega cikla je Eriksonova teorija stopenjskega razvoja osebnosti (Erikson, 1959, 1963). Erikson je definiral osem razvojnih stopenj v življenju posameznika, ločnica med posameznimi obdobji pa je kriza, kritično odločanje o nadaljnjem življenju, ki je lahko bolj ali manj zahtevno in temu primerno lahko traja nekaj mesecev ali celo nekaj let in pomeni pomembno življenjsko prelomnico. Življenjske prelomnice označuje konflikt med dvema nasprotjema (slika 1).

Pri svojem delu je izhajal iz psihoanalize, svojo teorijo osebnostnega razvoja pa je utemeljil na individualnih študijah primerov, pri čemer je opazoval načine, kako so posamezne osebnosti reševale krizo $\mathrm{v}$ določenih

\section{Slika 1: Osemsłopenjski model Eriksonovega osebnostnega razvoja}

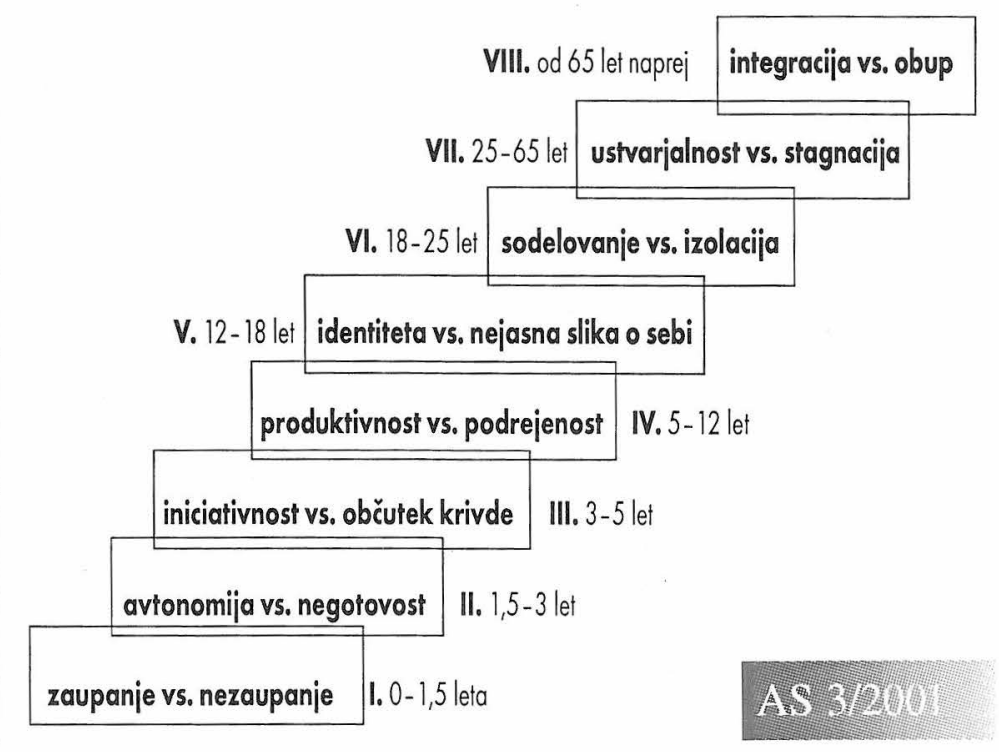


življenjskih obdobjih, in kot takšna je izjemno pomembna tudi za razumevanje razvoja kariere. Kadarkoli namreč govorimo o karieri in odločitvah $\mathrm{v}$ zvezi $\mathrm{z}$ njo, preprosto ne moremo zaobiti osebnostnega razvoja, ki ga določajo genetski in sociopsihološki dejavniki, vendar se bomo v nadaljevanju posvetili predvsem obdobju odraslosti in dejavnikom osebnostnega razvoja, ki je več ali manj vsem skupen, namerno pa prezrli individualne razlike med posamezniki, saj bi tako zašli na brezkončno področje psihološkega raziskovanja posameznika kot enkratne osebnosti. Prav tako se bomo ukvarjali s posameznikovim biosocialnim ciklom od obdobja adolescence, zanemarili pa obdobje otroštva, saj presega namen pričujočega dela.

Eriksonovi teoriji stopenjskega razvoja osebnosti (stage theory of personality) so sledili številni raziskovalci (Troll, 1975, Kimmel, 1974, Kalish, 1975, Bishof, 1976), ki so se trudili na podlagi njegove teorije določiti specifične življenjske naloge $\mathrm{v}$ posameznih obdobjih. Vsi ugotavljajo, da je večina življenjskih na$\log \mathrm{v}$ tesni korelaciji s starostjo, $\mathrm{z}$ veliko verjetnostjo lahko sklepamo, da je tako zaradi že omenjenih bioloških sprememb in močno zasidranih družbenih oziroma kulturnih norm, ki veljajo $\mathrm{v}$ določeni družbi. V vsaki starosti družba od posameznika pričakuje nekaj drugega (Neugarten, 1968). V naši

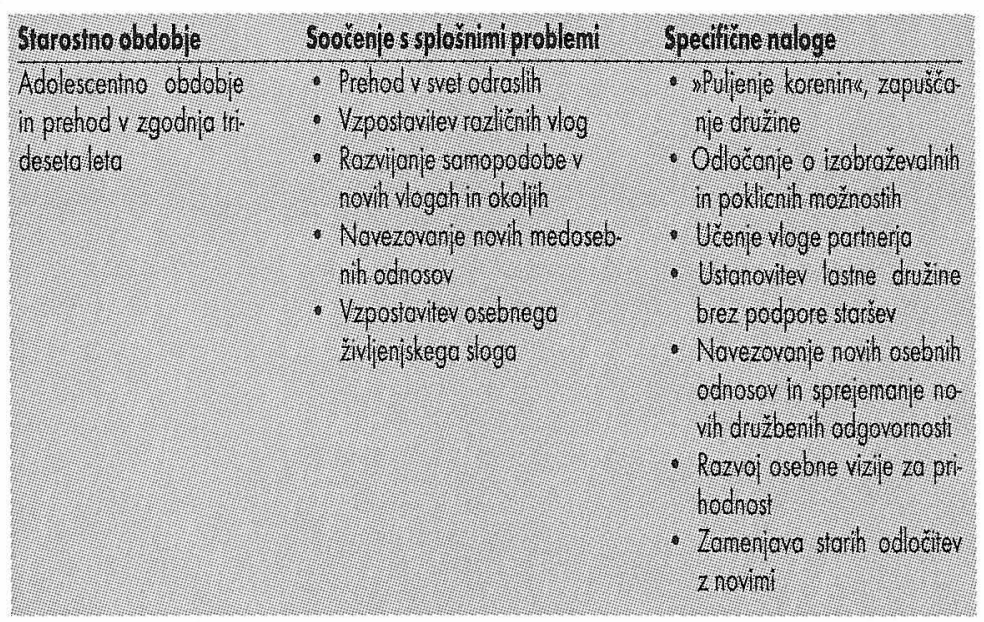
(zahodni) družbi določene življenjske prelomnice določa že pravni sistem: ko dopolnimo 18 let, smo »uradno« odrasli, lahko pridobimo vozniško dovoljenje in $\mathrm{v}$ pravnih zadevah odločamo sami. Druge življenjske prelomnice določa socialni sistem, na primer, kdaj se bomo upokojili, in navsezadnje je treba omeniti še številne individualne različice glede na to, $\mathrm{v}$ kateri starosti se bo posameznik lotil kakšne življenjske naloge. Toda kljub temu lahko naredimo kronološki pregled življenjskih nalog, ki jih omenjajo posamezni avtorji. Skušala sem jih urediti vzdolž kronološkega življenjskega kontinuuma osebnosti, od obdobja adolescence do posameznikove biološke smrti.

Prva velika prelomnica je za vsakogar prehod iz adolescence $v$ svet odraslosti, ki se zgodi nekje med 20. in 30. letom. To je obdobje, ko se posameznik iztrga iz vezi družine in »najde« sebe v svetu odraslih. Pogosto si prav v tem obdobju ustvari družino in hkrati gradi kariero. $\mathrm{V}$ tem obdobju je pred njim veliko zahtevnih nalog, toda to je tudi čas velikega entuziazma, idealizma in notranje energije, ki $\mathrm{mu}$ omogočajo lažje premagovanje problemov.

\section{Slika 2: Življenjske naloge $\mathbf{v}$ posameznikovem biosocialnem ciklu}

Prehod v trideseta leta je za večino obdobje prvega samoocenjevanja. Kje sem, kaj sem dosegel, ali je moja življenjska pot pravilna, ali se moje delo sklada $\mathrm{z}$ mojimi vrednotami ... Ideali izgubljajo svojo simbolno moč in posameznik postaja vse stabilnejši ali pa se popolnoma preusmeri. To je pogosto tudi obdobje večjih in pomembnejših kariernih odlo- 
čitev. Prav v obdobju tridesetih let največ posameznikov ne le menja službo, ampak popolnoma spremeni poklic. Realnost delovnega življenja, poroka, skrb za vzgojo otrok, finančne in druge odgovornosti razbija ideale dvajsetih let in sili posameznika $v$ različne zavezujoče odločitve. Ko enkrat te odločitve sprejme, se začne obdobje razmeroma stalnih obvez. V pogovornem jeziku se je za to obdobje oblikovala fraza »pognal je korenine« ali pa »ustalil se je«.

\begin{tabular}{|c|c|}
\hline Starosino ob dabje & Sooctenjes splośnimi probleni \\
\hline $\begin{array}{l}\text { Pozna dvoisera lete in } \\
\text { prehod y srednig tide } \\
\text { seta }\end{array}$ & 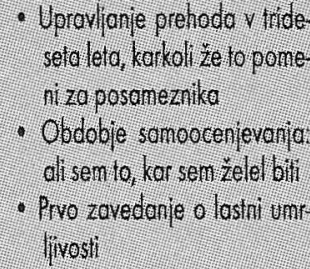 \\
\hline
\end{tabular}

V poznih tridesetih oziroma zgodnjih štiridesetih letih veliko posameznikov doživlja krizo srednjih let. Permanentne obveznosti, ki izhajajo iz prejšnjega obdobja so več ali manj izpolnjene, posledice teh obveznosti pa so pogosto v nasprotju z mladostniškimi sanjami, ambicijami in upi. Zanimivo, da je v tem obdobju tudi največ ločitev med zakonskimi partnerji. Kaj posameznika sili v konfrontacijo s samim seboj? Verjetno določena stopnja

\begin{tabular}{|c|c|c|}
\hline Starosino obdobje & Sooćenie s splośnimi problemi & Spectit'ne naloge \\
\hline Trideseta leto & 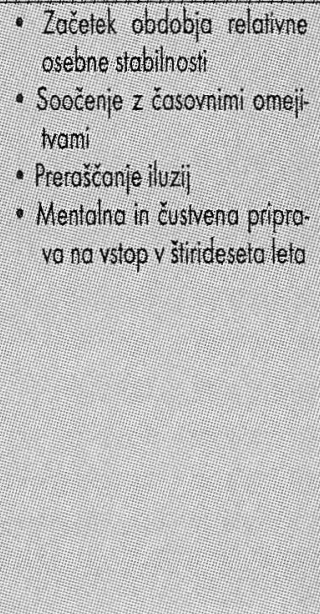 & 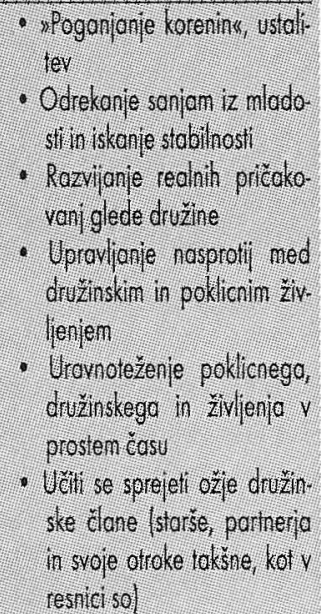 \\
\hline
\end{tabular}
ja.

\section{Specititine nologe}

- pregled odgovornosti v po Wict, druzin, skblizo otroke in socionivipletenosti

- Sprejemanje dolgorocinestio oblociley

- Sprejemanje odlocitev v zue 7iz zivlenisko usmerityilo

zavedanja o lastni umrljivosti na podlagi spoznanja, da je preživel že najmanj polovico življenja (Jacgues, 1965, Rogers, 1974). Posameznik se mora še naprej odločati o svojem življenju, obenem pa se naučiti živeti tudi s posledicami preteklih odločitev. Otroci odraščajo in lahko se bolj posveti svojemu zasebnemu življenju, ponovno postane bolj odprt do družbe in novih izzivov, ki mu jih ta ponu-

V poznih štiridesetih, zgodnjih petdesetih le-

tih veliko posameznikov doživlja »praznino« ob odhodu otrok od doma. To obdobje je še posebej težavno za nezaposlene matere, ki se spoprijemajo $\mathrm{z}$ velikimi spremembami $\mathrm{v}$ odnosih s partnerji, saj

\begin{tabular}{|c|c|c|}
\hline Storosino obdobje & Soorenje s splośnimi probleni & Spetficue nologe \\
\hline $\begin{array}{l}\text { Pozrog lideseta in } \\
\text { zgodnia slindeseta leta }\end{array}$ & 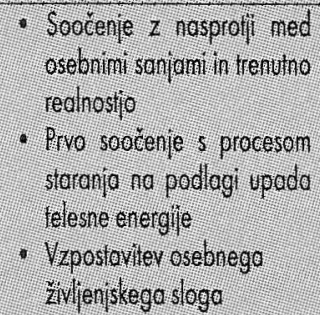 & 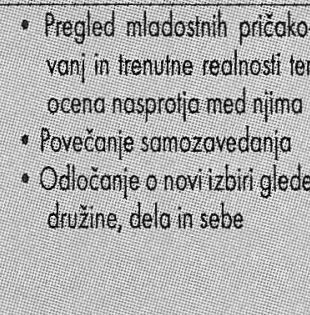 \\
\hline
\end{tabular}

morajo razviti povsem nov vzorec komuniciranja ob spoznanju, da imajo sedaj le še drug drugega.

Ko so rešeni problemi odhoda otrok od doma, posameznik spozna, da je resnično sam odgovoren za svoje življenje in znova razvije obdobje stabilnosti in zadovoljstva. To je obdobje poznih štiridesetih let. Posameznik obnovi stare socialne mreže in pospešeno socialno zori.
AS 31200 
Obenem pa rešuje težave, povezane $\mathrm{z}$ upadom fizične moči, motoričnih sposobnosti, telesno kondicijo, $s$ »konkurenco iz vrst mlajših generacij in drugimi simptomi »staranja Posamezniki v tem obdobju poročajo o občutkih, da se je »njihov čas iztekel« in da - če želijo še

\begin{tabular}{|c|c|c|}
\hline Starostno obdobje & Sooćenje s splósnimi problemi & Specifitine naloge \\
\hline $\begin{array}{l}\text { Obdobje po } \\
\text { Sestidesetem letu }\end{array}$ & 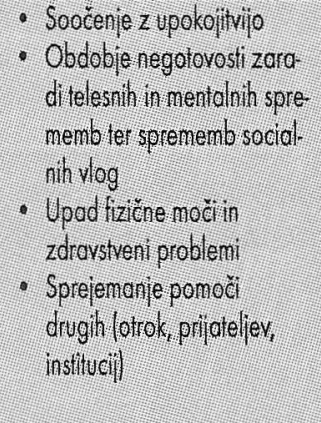 & 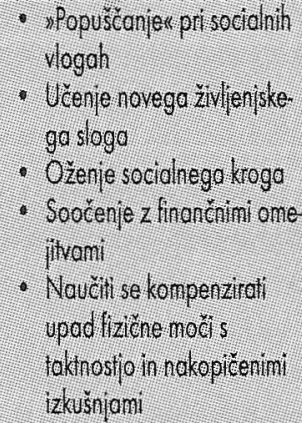 \\
\hline
\end{tabular}
kaj prispevati družbi oziroma organizaciji - morajo to prispevati zdaj. To je tudi čas, ko bi se moral začeti posameznik na osebni ravni začeti pripravljati na obdobje upokojitve in na morebitne spremembe življenjskega sloga, ki izhaja iz drugačnega finančnega, socialnega in zdravstvenega statusa.

\begin{tabular}{|c|c|c|}
\hline Siarosino obdobje & Soocenjes splošnimi problemi & Specificicnenaloge \\
\hline Pozno sinideseta leta & 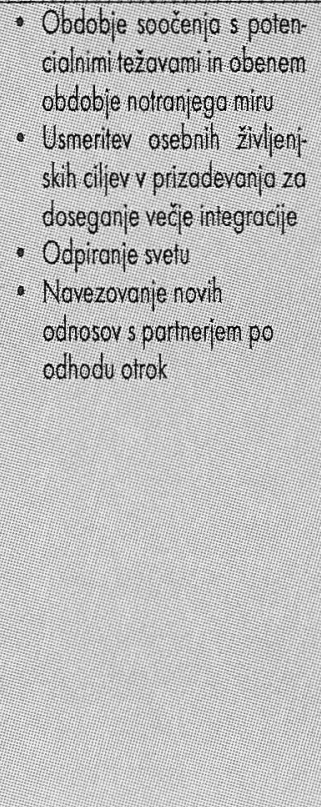 & 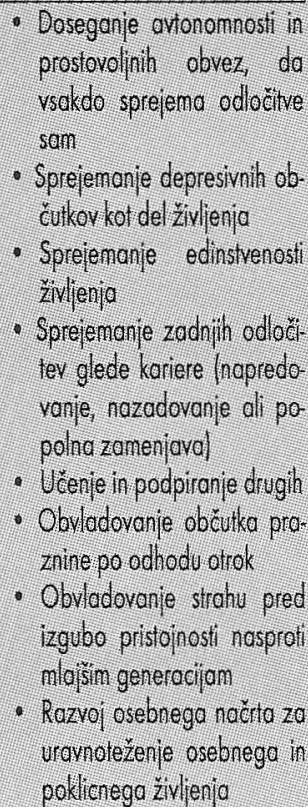 \\
\hline
\end{tabular}

Obdobje po 60. letu je obdobje velikega prehoda, povezanega $\mathrm{z}$ upokojitvenim statusom. Za tiste, ki so finančno dobro pripravljeni, je to obdobje razmeroma lahko obvladljivo. Hujše je za tiste, ki se jim standard življenja bistveno spremeni. Tudi zdravstveni problemi

se začnejo stopnjevati in obenem posamezniki v tem obdobju že doživljajo smrt bližnjih prijateljev ali življenjskega partnerja. Zaradi zdravstvenih težav postajajo spet odvisni.

Če se posameznik uspešno prebije skozi različne naloge v starosti, sprejme kompromise, se nauči ceniti modrost in izkušnje s tem, ko mu upadajo fizične sposobnosti, doseže integracijo, vidi svoje življenje kot plodno in ustvarjalno, torej kot koristno preživet čas. Tak posameznik s ponosom in zadovoljstvom gleda na svojo preteklost in življenjske odločitve ter dosežke. Nasprotno pa ga lahko obup in razočaranje razjedajo spričo dejstva, da ima za seboj veliko napačnih odločitev ali sploh nobene in da dejansko nima več priložnosti, da bi zamujeno nadomestil (Brečko, 1997).

\section{DINAMIČNOST KARIERNEGA CIKLA}

Biosocialni cikel bomo skušali primerjati s kariernim ciklom s predpostavko, da sta oba cikla med seboj tesno povezana zaradi kronološke starosti in družbenih norm. Pojem kariera $v$ zvezi s tem ni omejen na določen poklic, ampak opazujemo splošen prerez poklicne kariere, faze in stopnje, ki so z večjimi ali manjšimi odmiki značilne za vse poklice, tudi za svobodne. Gre bolj za interno kariero, torej za razvoj posameznikove poklicne poti v okviru ene organizacije, ki temelji predvsem 
na osebnih izkušnjah in pripovedovanju ljudi (Shein, 1977, Brečko, 2001). Pri tem bom abstrahirala individualne razlike med posamezniki in razlike med posameznimi poklici ter se osredinila predvsem na temeljni vzorec razvoja kariere na podlagi primerjave med posamezniki različne starosti, ki opravljajo sicer zelo različne vrste dela oziroma so se zapisali zelo različnim poklicem.

Prva in morda najponembnejša razlika, ki jo lahko takoj opazimo med biosocialnim življenjskin ciklom in kariernim ciklom, je gotovo ta, da ima vsakdo svoje $\gg$ osebnox Z̈ivjenje, ni pa nujno, da ima vsak poklicno kariero. Druga pa je ta, da ima posameznik nedvomno večji vpliv na karierni cikel kot na biosocialni. Kariero lahko pretrga, ji spremeni smer, se ji povsem odpove ... Karierni cikel lahko različno usmerja posameznik sam. Prav tako pa ima na karierni cikel velik vpliv tudi delovna organizacija s sistemi napredovanja, spodbujanja in zagotavljanja prilożnosti za izkazovanje posameznikovih ustvarjalnih sposobnosti.

Ljudje lahko ostanejo že zgodaj brez zaposlitve, lahko spremenijo poklic v okviru iste organizacije, napredujejo ali pa tudi nazadujejo v različnih letih življenja. Organizacije lahko pretrgajo kariero posameznika zaradi večjih tehnoloških sprememb, naredijo napako in omogočijo napredovanje napačni osebi, odpuščajo in še kako drugače posredno in neposredno vplivajo na posameznikovo kariero. V nadaljevanju se bomo zato ukvarjali predvsem z idealnim modelom posameznikove kariere, torej s tem, kako naj bi bil videti uspešen karierni cikel. Treba pa je takoj poudariti, da veliko posameznikov idealnega modela kariernega cikla ne doseže in da čutijo, da so na določenih točkah zgrešili pravo smer (Brečko, 2001) Takšni in podobni občutki posameznikov pa nas lahko neposredno navaja- jo k spoznanju, da niso uspešno izvedli kritičnih tranzicijskih prehodov v kariernem ciklu.

\section{VEČDIMENZIONALNOST KARIERNEGA CIKLA}

Stopnje, problemi in naloge, s katerimi se srečujemo pri razvoju kariere, so bolj ali manj sinteza več razvojnih teorij (Miller in Form, 1951, Ginzberg 1951, Havighurst, 1964, Rapoport, 1970, Sofort, 1970, Shein 1971, Hall, 1976, Dalton, Thompson in Price, 1977). Vsekakor je težko določati temeljne dejavnike in stopnje kariernega razvoja zaradi velike razpršenosti poklicev, nastajanja novih in izginotja nekaterih starejših poklicev in navsezadnje tudi zaradi pomanjkanja kakovostnih longitudinalnih študij. Iz študij, ki so na voljo, pa lahko kljub temu naredimo grob prerez osnovnih dimenzij.

Večina posameznikov, ki so zaposleni v organizacijah, se premika vzdolž hierarhične lestvice. To pomeni, da med kariero večkrat napredujejo in dosežejo določen položaj $\mathrm{v}$ organizaciji. Razlike so seveHorizontalni, vertikalni premiki ter premiki proti centru tvorijo večdimenzionalnost kariernega cikla. da v tem, da v nekaterih organizacijah dosežejo najvišje položaje tik pred upokojitvijo, v drugih pa lahko zelo hitro napredujejo, lahko bi rekli, da do vodilnega položaja v nekaterih organizacijah vodi veliko stopnic, $\mathrm{v}$ drugih $\mathrm{pa}$ manj.

Sočasno pa posameznik napreduje tudi na svojem strokovnem področju in gre torej za karierne premike vzdolž funkcionalne oziroma tehnične dimenzije. Pri posameznikih, ki se že zgodaj zapišejo specializaciji, je opaziti le malo premikov vzdolž te dimenzije. Drugače pa je pri posameznikih, ki pogosto menjajo področja, na primer nekdo, ki se je iz proizvodnje premaknil v prodajni oddelek in nato $\mathrm{v}$ oddelek za marketing ... Ka- 


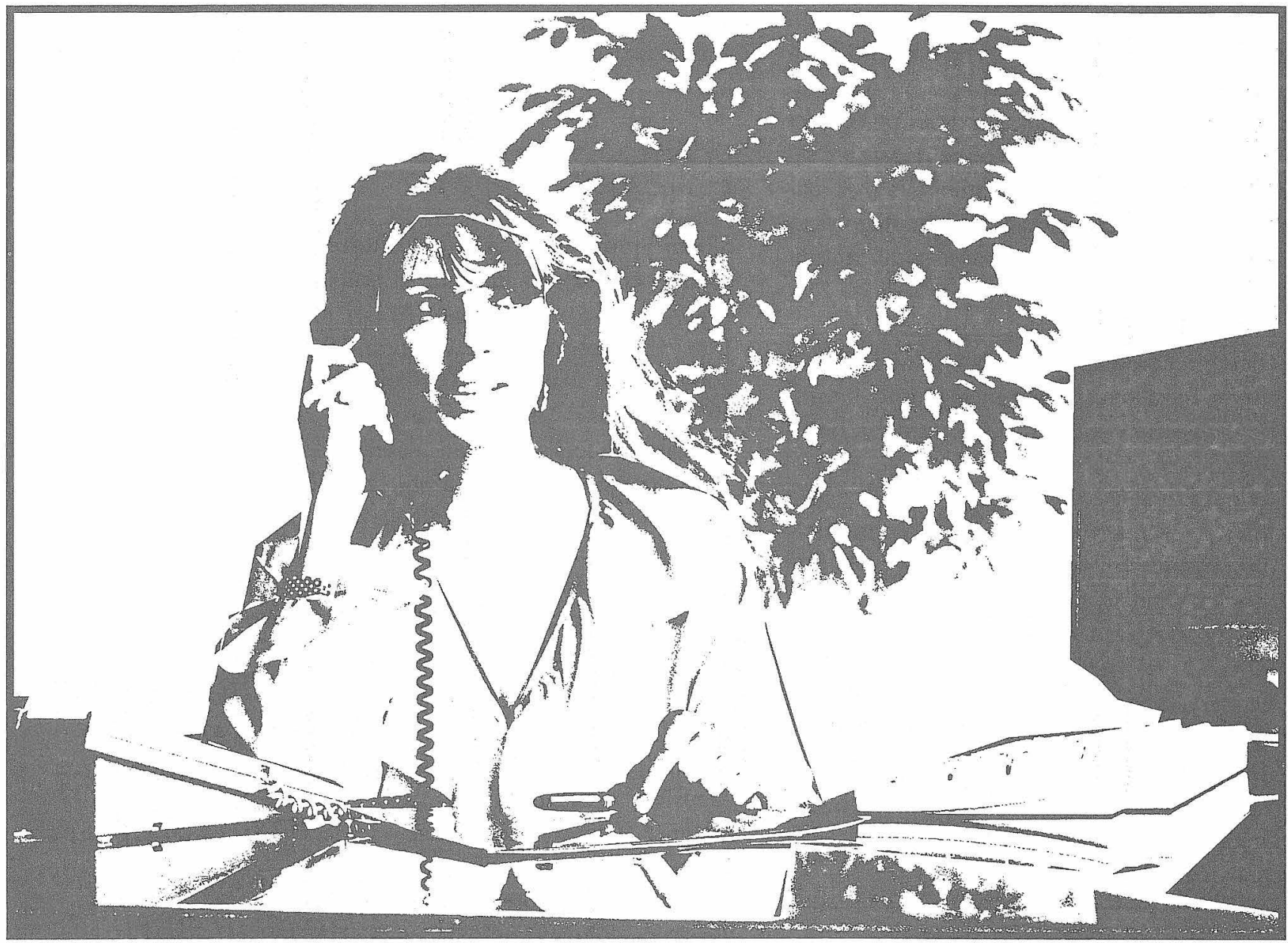

dar govorimo o drugi karieri, pravzaprav pogosto govorimo o takšnih premikih, torej o premikih vzdolž funkcionalne in tehnične dimenzije. Kakorkoli že, premike po hierarhični lestvici lahko imenujemo vertikalni karierni razvoj, premike vzdolž funkcionalne dimenzije pa horizontalni ali lateralni karierni razvoj.

Tretja in najmanj otipljiva dimenzija razvoja kariere pa je premik proti »centru« organizacije, kar pomeni, da je posameznik razvil pripadnost do organizacije do take stopnje, da je postal njen cenjen član in si pridobil status notranjega svetovalca. Često je vertikalni karierni razvoj povezan s premiki proti centru, ni pa nujno.

\section{STOPNIE IN NALOGE V KARIERNEM CIKLU}

Stopnje in naloge v kariernem ciklu, prikazane na sliki 3, so značilne predvsem za karierni razvoj posameznikov, zaposlenih v organizacijah. Toda tudi pri samostojnih podjetnikih oziroma posameznikih, ki so samozaposleni, in tistih, ki so se zapisali svobodnemu poklicu, lahko najdemo določene podobnosti, čeprav jih ne moremo povsem izenačiti. V kariernem ciklu je mogoče prepoznati devet stopenj in vsaki izmed teh stopenj je moč pripisati splošne naloge in probleme, s katerimi se posamezniki srečujejo. Prav tako so te stopnje povezane tudi $\mathrm{z}$ določeno starostjo, ne glede na možne individualne različice, razpone v letih. 
Slika 3: Življenjske naloge in stopnje v kariernem ciklu

\begin{tabular}{|c|c|c|}
\hline Slopina & Soocente s splošnimi groblemi & Spectificne nologe \\
\hline 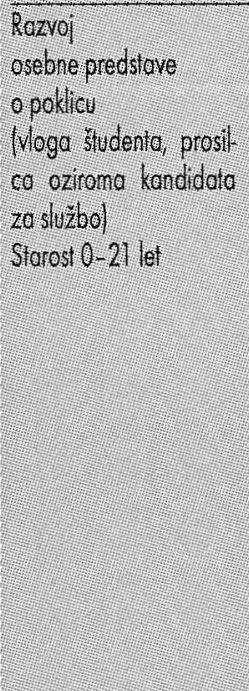 & 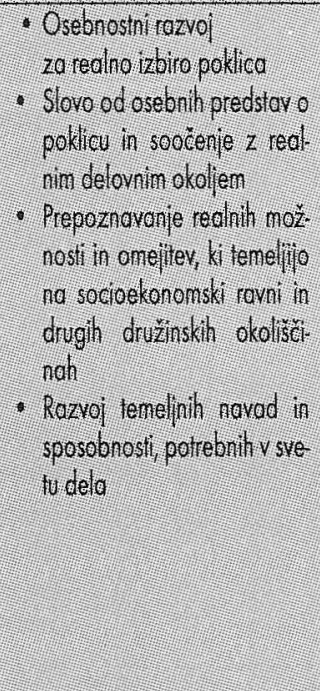 & 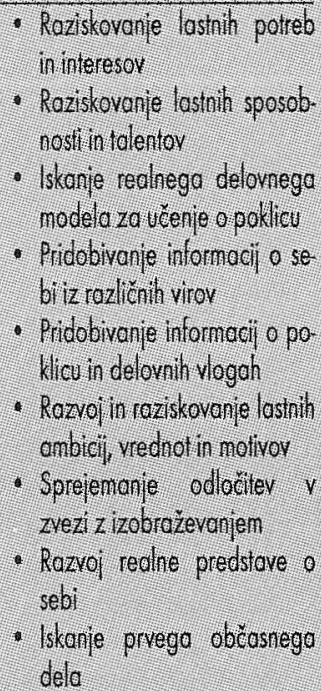 \\
\hline
\end{tabular}

nega, pri čemer mora opravljati tudi »umazane« posle oziroma delo, pri katerih ne more izraziti svojih sposobnosti. Sposobnost uspešno krmariti med neodvisnostjo ter odvisnostjo in najti svoje področje delovanja je ključ za razvoj zgodnje stopnje kariere.

Ko posameznik pridobi status polnopravnega člana $v$ organizaciji, se začne njegova pot iskanja področja, kjer bi lahko največ

Za izbiro poklica je pomembno že zgodnje otroštvo, ko posameznik pridobiva vpogled vase in se seznanja s poklicnimi možnostmi. Glavni proces razvoja kariere v tem obdobju obsega pridobivanje verodostojnih informacij o sebi, poklicih, družbeni realnosti in odločanje o optimalni izbiri, pri čemer bi lahko posameznik izkazal svoje zmožnosti in dosegal zadovoljstvo ter osebnostno rast.

Vstop v organizacijo oziroma določen poklic je pomemben del ali pa kar prelomnica procesa osebnostne rasti. Na eni strani mora posameznik pokazati prizadevnost, iniciativnost in pripravljenost na novo učenje, s čimer pokaže, da bi želel prispevati k organizaciji, po drugi strani pa se mora naučiti vloge podreje-

\begin{tabular}{|c|c|c|}
\hline Siopnia & Soocenje s splosnimi problemi & Specticne nologe \\
\hline $\begin{array}{l}\text { Temeino usposoblionje } \\
\text { Sterost } 16-25 \text { lef }\end{array}$ & 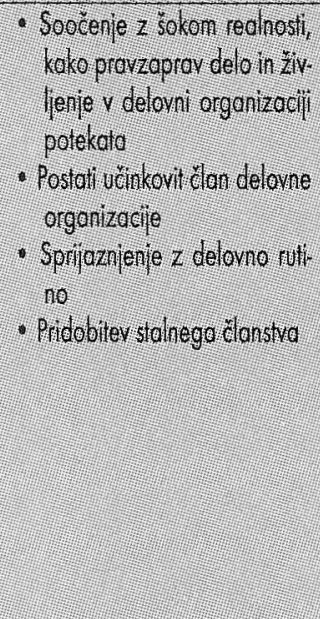 & 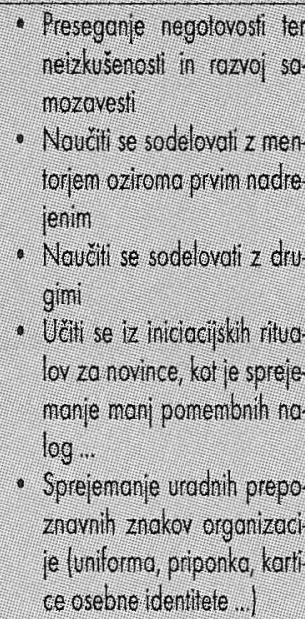 \\
\hline
\end{tabular}

\begin{tabular}{|c|c|c|}
\hline Siopria & Sooienjes splosnimiproblemi & Specitimene naloge \\
\hline $\begin{array}{l}\text { lstop y svet delat } \\
\text { lylogo proravikal } \\
\text { starost } 15-25 \text { let }\end{array}$ & 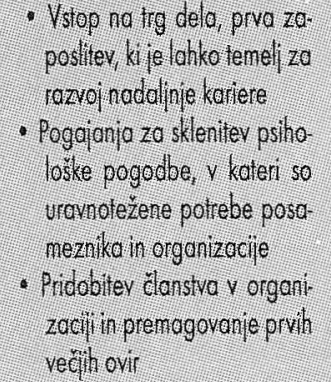 & 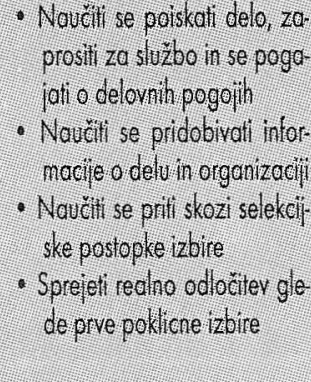 \\
\hline
\end{tabular}

pripomogel $\mathrm{k}$ skupnosti, katere član je, v tem primeru delovni organizaciji. Posameznik mora biti pripravljen prevzemati odgovornost za področje, ki ga je prevzel, ne da bi bil potreben še nadzor. Napredovanje ali lateralni premiki so lahko posledica 


\begin{tabular}{|c|c|c|}
\hline Stopoja & Sooćenje s splossnimi problemi & Specititune nologe \\
\hline $\begin{array}{l}\text { Polnoprovno elanstvo } \\
\text { Sirost } 17-30 \text { let }\end{array}$ & 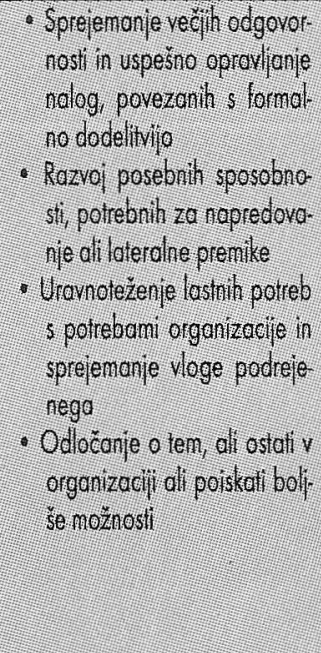 & 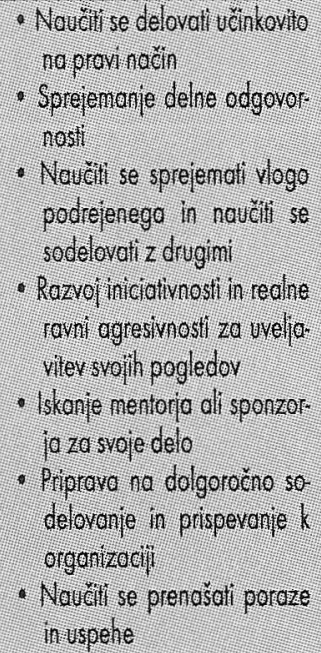 \\
\hline
\end{tabular}

volj izkušenj, se začne premik k srednji karieri, za katero sta značilna dva povsem nova problema: kako izrabiti svoje izkušnje in modrost prek tehničnih ali drugih posebnih spretnosti ter kako postati generalist in kako izpolniti osebno razvojno težnjo postati mentor drugim.

Veliko posameznikov v zgodnjem kariernem obdobju čuti pomoč in vodenje drugih, starejših v organizaciji. Ko se premikajo za stopnjo navzgor $\mathrm{v}$ kariernem razvoju, ne čutijo le emocionalne potrebe pomagati drugim, ampak želijo predvsem prenesti svoje znanje in izkušnje na mlajše generacije.

Postati mentor mlajšim je pravzaprav naravni rezultat procesa razvoja srednje kariere.

$\mathrm{Za}$ večino posameznikov se začne $\mathrm{v}$ obdobju

teh prizadevanj, ni pa nujno. Gre predvsem za nekakšno ultimativno preverjanje med posameznikom in organizacijo $\mathrm{z}$ vidika obojestranske zadovoljitve potreb $\mathrm{v}$ daljšem obdobju. To obdobje se simbolično konča s pridobitvijo stalnega članstva.

Na določeni stopnji, ko si posameznik pridobil do-

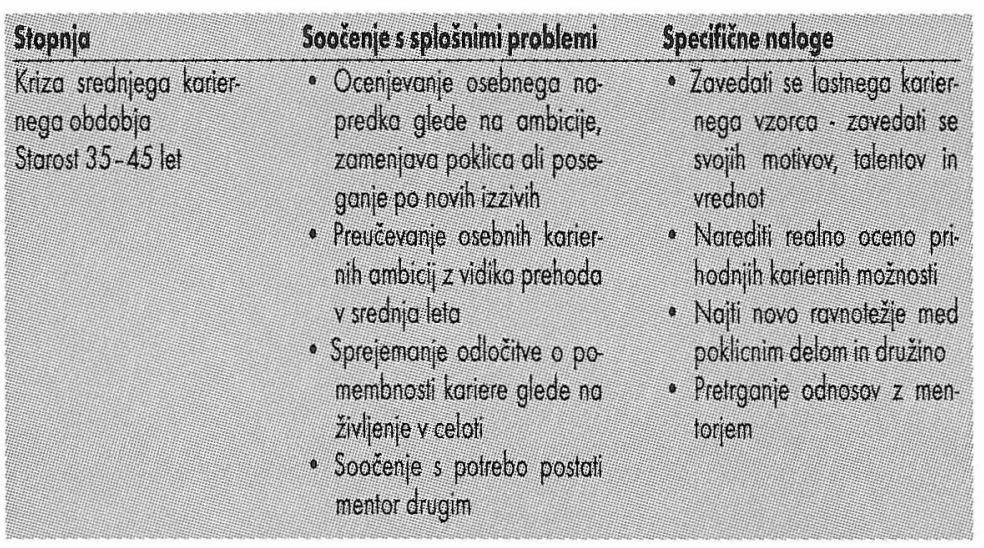

med 35. in 45. letom starosti določena kriza, ko se sprašujejo, ali so uresničili ambicije $\mathrm{v}$ zvezi z izbiro poklica, pa tudi, kakšno težo jim pomeni kariera $\mathrm{z}$ življenjskega vidika. To je obdobje, ko se večinoma dokaj dobro zavedajo svojih zmožnosti in omejitev, prav tako pa dobro predvidevajo, kakšna bo prihodnost organizacije. Na podlagi teh informacij se začne proces ocenjevanja razlik delovnega in osebnega okolja, kot so družina in potrebe, ki iz nje izhajajo. To obdobje je lahko izrazito dramatično, če izbruhnejo nasprotja med delovnim in družinskim okoljem. Stres je lahko tudi posledica spoznanja, da bomo morali $v$ delo vložiti še-več 


\begin{tabular}{|c|c|c|}
\hline Siopnia & Soocenjes splośnimi problemi & Specititne nologe \\
\hline $\begin{array}{l}\text { Pozna kariera } \\
\text { Starost od } 40 \text {. leta do } \\
\text { upokoitve }\end{array}$ & 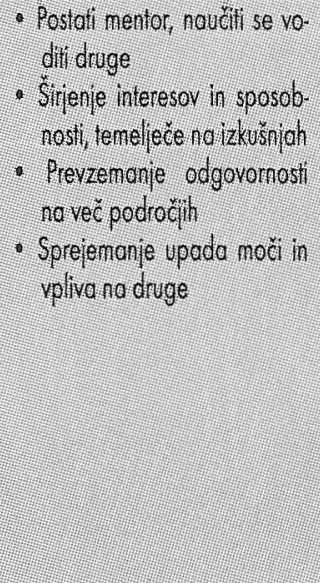 & 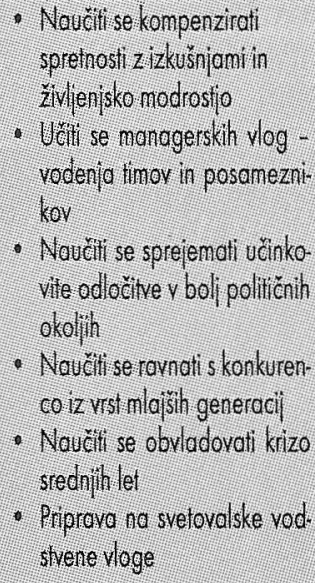 \\
\hline
\end{tabular}

vpletenosti v poklicno delo, uspešnosti oziroma neuspešnosti prehojene karierne poti in navsezadnje do interkacije vseh teh dejavnikov $\mathrm{z}$ družinskim in osebnim položajem. Temeljni problem $\mathrm{v}$ tem obdobju je sprijaznjenje $\mathrm{z}$ bližajočim se koncem poklicne kariere in opuščanje dosedanjih poklicnih vlog. To je odvisno predvsem od stopnje zadovolj- osebne energije za zadovoljitev finančnih potreb družine.

Drugi aspekt krize srednjega kariernega obdobja je sprejemanje dejstva, da nas »čas prehiteva« oziroma da so nas mlajše generacije na strokovnem področju prehitele in da ne znamo več slediti novemu znanju. Srečujemo se s konkurenco mlajših, bolje usposobljenih generacij in obenem čutimo upad osebne energije. Za posameznike, ki so postali generalisti in se pomaknili na višje adminstrativne ali vodstvene položaje, je to manj akuten problem. Večji problem je za tiste, ki so se odločili ostati na ozkem, specialnem področju.

Kasnejša karierna obdobja je težko strniti, saj so zelo odvisna od vrste kariere in stopnje, do katere se je posameznik pomaknil proti vodilnim in vodstvenim položajem, do stopnje

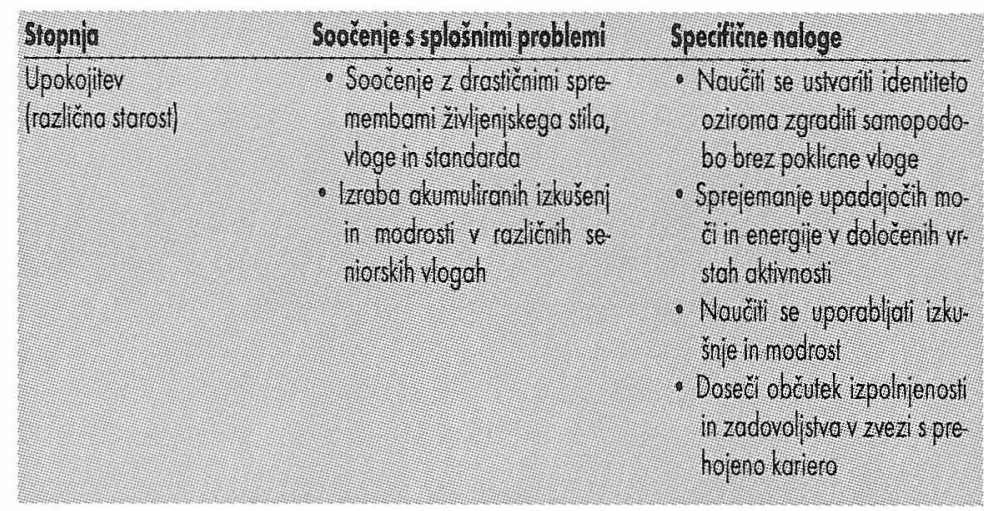

stva oziroma nezadovoljstva s prehojeno karierno potjo.

Starostna obdobja posameznih kariernih obdobij zelo nihajo in jim ni moč postaviti natančnejše kronološke ločnice, kajti posamezniki se pomikajo skozi naštete stopnje zelo različno, glede na zahteve poklica in na osebnostno zrelost. Kdaj in kako se premikajo skozi te karierne stopnje, je odvisno tudi od

\begin{tabular}{|c|c|c|}
\hline Siopria & Soocenje s splossnimi problemi & Specintene nologe \\
\hline $\begin{array}{l}\text { Upadanie moči in niza } \\
\text { je stopnje vpletenosil } \\
\text { Starost od } 40 \text {. leta do } \\
\text { upokoitive }\end{array}$ & 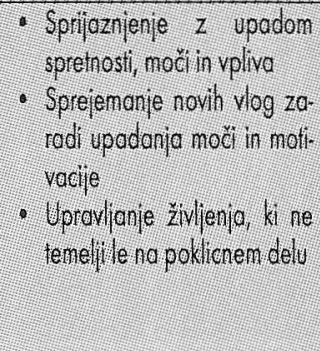 & 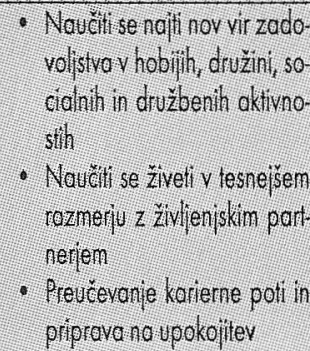 \\
\hline
\end{tabular}
njihovega osebnega vrednostnega sistema, motivov, ambicij, situacijskih dejavnikov, same kulture organizacije, celo ekonomskih in gospodarskih razmer v danem okolju ... Toda dejstvo je, da se vsi srečujemo z opisanimi te- 
žavami ter problemi in se spoprijemamo $\mathrm{z}$ življenjskimi nalogami v določenih kronološko sicer premakljivih starostnih obdobjih, ki smo jih prav zato ohlapno definirali. Toda $\mathrm{z}$ večjim vpogledom $v$ karierni cikel lahko postane naše življenje predvidljivejše in načrtnejše. Organizacije lahko s poznavanjem posameznikovega kariernega in biosocialnega cikla sistematično načrtujejo razvoj kariere in oblikujejo takšen organizacijski sistem, ki bo upošteval tudi razvojni vidik posameznikove osebne in poklicne rasti.

\section{SKLEPNE MISLI}

Na podlagi strokovnih del mnogih avtorjev in preučevalcev posameznikove osebnostne rasti ter strokovnjakov za razvoj delovne kariere smo analizirali biosocialni in karierni življenjski cikel in ugotovili, da je karierni cikel tesno povezan $\mathrm{z}$ biosocialnimi stopnjami $\mathrm{v}$ posameznikovem življenju.

$\mathrm{S}$ poznavanjem temeljnih zakonitosti biosocialnega in kariernega cikla bi pridobila posameznik in organizacija. Posameznik bi lahko učinkovito oblikoval osebni karierni načrt $\mathrm{z}$ vidika uravnotežene porabe osebne energije, organizacije pa bi z upoštevanjem njegovih biosocialnih značilnosti lahko uěinkoviteje usmerjale kariero zaposlenih jim pri tem pomagale oziroma ustvarile takšen sistem izobraževanja in usposabljanja, ki bi posamezniku in organizaciji prinesel boljše rezultate.

$\mathrm{V}$ zvezi s tem pa je povsem utemeljeno vprašanje oblikovanja učnih vsebin s področja načrtovanja kariere, ki bi lahko postale del obveznega šolanja oziroma verificiranih programov na srednji, visokošolski in univerzitetni stopnji obvezen sestavni del osebnega svetovanja za razvoj kariere, pa tudi obvezna učna snov za izobraževalne programe za brezposelne.

\section{VIRI IN LITERATURA}

Allinger, G. M. in Janak, E. A. »Kirkpatrick's Levels of Training Criteria: Thirty years later « Personnel Psychology, 42, 1989, str. 331-340.

Brečko, D. Kako se odrasli spreminjamo, Didakta 1998.

Brečko, D. Karierna sidra in načrtovanje izobraževanja, raziskava, ki poteka, 2001

Cascio, W. F. Costing Human Resources: The Financial Impact of Behavior in Organizations. Boston, MA: Kent, 1987.

Chao, G. T., O'Leary-Kelly, A., Wolfs., Klein, H. J., in Gardner, P. D. »Organizational Socialization: Its Content and Consequences«, Journal of Applied Psychology, 79, 1994, str. 450-463.

Dixon, N. Relationship between Training Responses on Participants Reaction Forms and Post-test Scores. Human Resources Development Quartelry, 1(2), 1991, str. 129-137.

Holton, E. F. »Performance Domains: Bounding the Theory and Practice « Advances in Developing Human Resources, Washington, D. C.: ISPI Press, 1998.

Katz, R. Organizational Stress and Early Socialization Experineces, v: T. A. Beehr and R. S. Bhagat (Eds.), Human Stress and Cognition in Organizations. New York: John Wiley \& Sons, 1985, str. 117-139.

Knowles, Malcolm S. The Modern Practice of Adult Education: From Pedagogy to Andragogy, Englewood Cliffs, Cambridge, 1980.

Knowles, Malcolm S. Andragogy in Action, San Francisco: Jossey-Bass, 1984.

McGarrell, E. J., Jr. »An Orientation System that Builds Productivity « Personnel, 60, Vol. 6, 1983, str. 32-41.

Ostroff, C. in Kozlowski, S. W. J. Organizational Socialization as a Learning Process: The Role of Information Acquisition. Personnel Psychology, Vol. 45, 1992, str. 849-874.

Swanson; R. A. Human Resources Development: Performance in Key, Human Resources Development Quarterly, 6 (2), 1995, str. 207-213.

Shein, E. H. Career Dynamics: Matching individual and organizational needs, Addison-Wesley Publishing Company, 1978.

Swanson; R. A. in Holton, E. F. Human Resources Development Handbook: Linking Research and Practice. San Francisco: Berrett-Koehler, 1997.

Wachter, M., Druga kariera; seminarsko gradivo, GV Izobraževanje, 2001.

Weiss, H. M. Subordinate Imitation of Supervisor Behavior: The Role of Modeling in Organizatioanl Socialization. Organizational Behavior and Human Performance, Vol. 19, 1977, str. 89-105. 